\title{
BMJ
}

\section{Risk factors at medical school for subsequent professional misconduct: multicentre retrospective case-control study}

\author{
Janet Yates, research fellow in medical education, David James, foundation director of medical education
}

\begin{abstract}
Medical Education Unit, University of Nottingham Medical School, Queen's Medical Centre, Nottingham NG7 2UH

Correspondence to: J Yates janet.yates@nottingham.ac.uk

Cite this as: $B M J$ 2010;340:c2040 doi:10.1136/bmj.c2040
\end{abstract}

\section{ABSTRACT}

Objective To determine whether there are risk factors in a doctor's time at medical school that are associated with subsequent professional misconduct.

Design Matched case-control study.

Setting Records from medical schools and the General Medical Council (GMC).

Participants 59 doctors who had graduated from any one of eight medical schools in the United Kingdom in 1958-

97 and had a proved finding of serious professional misconduct in GMC proceedings in 1999-2004 (cases); 236 controls (four for each case) were selected by systematic sampling from matching graduation cohorts. Case-control status was revealed by the GMC after completion of data entry.

Main outcome measure Odds ratios for being a "case," with multivariable conditional logistic regression of potential risk factors including pre-admission characteristics and progress during the course. These data were obtained from anonymised copies of the students' progress files held by their original medical schools.

Results Univariate conditional logistic regression analysis found that cases were more likely to be men, to be of lower estimated social class, and to have had academic difficulties during their medical course, especially in the early years. Multivariable analysis showed that male sex (odds ratio 9.80, 95\% confidence interval 2.43 to $39.44, \mathrm{P}=0.001$ ), lower social class (4.28, 1.52 to $12.09, \mathrm{P}=0.006)$, and failure of early or preclinical examinations $(5.47,2.17$ to $13.79, \mathrm{P}<0.001)$ were independently associated with being a case.

Conclusions This small study suggests that male sex, a lower socioeconomic background, and early academic difficulties at medical school could be risk factors for subsequent professional misconduct. The findings are preliminary and should be interpreted with caution. Most doctors with risk factors will not come before the GMC's disciplinary panels.

\section{INTRODUCTION}

In recent years, several high profile cases have led to media interest and public concern regarding doctors who fail to maintain expected professional standards. Notable cases have been those of Harold Shipman and the doctors involved in the paediatric cardiac surgery cases at Bristol. ${ }^{2}$ Besides these prominent cases, however, there are many other complaints made against doctors each year. Minor problems can be dealt with internally by the employing organisation, such as a hospital trust, but others will be referred to the United Kingdom's General Medical Council (GMC), which regulates the registration of doctors. ${ }^{3}$

A relatively small number of doctors become the subject of serious complaints. Research into this issue, however, is important to all doctors to protect the integrity of the profession and maintain public confidence. Efforts to ensure that future doctors have the necessary personal characteristics begin during the admission processes for medical school, guided by recommendations from the GMC and the Medical Schools Council (formerly the Council for Heads of Medical Schools). ${ }^{45}$ Students who make poor academic progress or display unsatisfactory behaviour might be seen by the medical school's progress committees or fitness to practise panels. Most medical schools will endeavour to terminate the course of a student who seems unsuitable for graduation as a doctor, but this process might be resisted through appeal mechanisms. Beyond graduation, current initiatives are aimed at the monitoring of performance through regular appraisal. ${ }^{6-8}$ Historically, there has been no mechanism to track and evaluate doctors' performance once they have graduated, particularly to identify and support those who performed less well as students. We speculated that some of the doctors who experience difficulties in their professional lives, and might eventually come before the GMC for serious misconduct, might also have had problems at medical school. To our knowledge, there is no published research in the UK that has attempted to link students' course records with subsequent proceedings for professional misconduct. There is some evidence from the United States, where doctors disciplined by state medical boards seem more likely to have "negative comments" in their student file and to have slightly poorer academic records. ${ }^{910}$

In a pilot study conducted in collaboration with the GMC in 2006-7, we analysed the student records of 16 doctors who had appeared before GMC disciplinary panels compared with cohort matched controls in a $1: 4$ ratio (these doctors had all trained at Nottingham). We found a consistent pattern of poorer academic 
achievement in the "cases," with similar risk factors to those we have previously reported in "struggling" students. ${ }^{11}$ In the light of that pilot study we carried out a multicentre case-control study to determine whether there are any factors in a doctor's record from medical school that are associated with an increased risk of subsequent professional misconduct.

\section{METHODS}

This was a collaborative study between Nottingham University Medical School, the GMC's research and development advisory board, and seven other medical schools. These medical schools were chosen because they retained students' records indefinitely and expressed an interest in participating in the research.

The GMC identified the cases from each of the partner medical schools. They were doctors who had had a "finding in fact" for professional misconduct between January 1999 and December 2004, excluding those with health problems or who had requested voluntary erasure from the medical register. The GMC also identified four matched controls for each case, using a systematic sampling procedure (see appendix 1 on bmj.com). The controls were doctors who had graduated from the same university in the same year and were fully registered, currently practising, and had never been under investigation.

The names of the cases and controls, together with a unique study ID, were transmitted confidentially to each medical school. The student files were copied and fully anonymised before being sent to Nottingham for data entry, identified only by the study ID. This procedure ensured total confidentiality and therefore complied with data protection requirements. All available data (sociodemographic factors and course progress) were entered on a customised database. Parental occupation of the father, as supplied by students, was used to estimate social class, using three independent reviewers and the traditional five category registrar general's scheme ${ }^{12}$ (see appendix 1 on bmj.com). These data were subsequently collapsed into higher (classes I-III) or lower (IV-V).

Since the introduction of the UCCA system in the 1960s (Universities Central Council on Admissions, now UCAS, Universities and Colleges Admission Service), admission panels have been able to read free text, unstructured references or statements of each candidate's academic ability and suitability for medicine, usually written by the student's head teacher. Review of these statements has been included in many admissions procedures, including Nottingham's, because they might identify potential problems. Until recent years these reports were confidential, so that head teachers could allude to any doubts they had about an applicant's ability or aptitude for medicine. Now that students see their own reference it is most unlikely that the head teacher will include any such comments, and as a consequence the statements are bland and generally uninformative. In the more historical context of our study there was still potential "negative" value because the student could not see what the head teacher had written.

In our study, three experienced members of the medical admissions panel at Nottingham reviewed the referee's statement provided for each student (case and control) and scored each for the presence of "negative comments" - any remarks that might indicate a lack of academic ability, poor attitude, or any other potentially undesirable characteristics. A check list was provided, based on earlier research at Nottingham. ${ }^{11}$ Each assessor gave each statement a score of "no negative comments," "minor negative comments," "moderate negative comments," or "major negative comments" (see appendix 2 on bmj.com). Data from the three assessors were entered on a separate database and a single "negative comments" score was generated for each student by using the majority view or average value of the three assessors' scores. This single comment score was generated before case/control status was revealed. Those students with a final rating of "moderate" or "major" comments were flagged as having "relevant negative comments." The reviewers did not have access to any other part of the student's application or medical school record.

Students' university records were examined closely for all marks or grades and indicators of overall progression, including additional years spent on the course for repeated examinations or for intercalated degrees. If it was not clear whether a low mark or grade was actually classed as a fail, or whether the re-sitting of an exam had required the student to repeat that part of the course, we did not denote it as such, thereby erring on the side of caution. Examination progress for each student was estimated as high, average, or below average within every case-control group and subsequently collapsed to a binary variable (high/average or poor). Any "adverse remarks" were recorded verbatim.

After completion of the database, the GMC supplied the case-control status and anonymised summary details of each case. This avoided any potential bias during data entry. (Full details of data handling are given in appendix 1 on bmj.com.)

\section{Data analysis}

After descriptive analysis in SPSS v16, we used conditional logistic regression (Stata v10) to calculate odds ratios and 95\% confidence intervals for the explanatory variables against the outcome variable of being a "case." This was done firstly as a univariate analysis, then as a multivariable analysis, initially including all explanatory variables then consecutively dropping the least significant one until all included variables were significant at $\mathrm{P}<0.05$. As there were some missing data we carried out an additional analysis using multiple imputation. We used the ICE procedure in Stata to obtain 10 imputed datasets and combined effect estimates and standard errors using Rubin's rules.

\section{Power statement}

With 59 cases and four matched controls for each case, a 5\% significance level, and assuming a correlation of 
0.2 for exposure between cases and matched controls, the study had $89 \%$ power to detect an odds ratio of 3 or more when $20 \%$ of controls are exposed, and $74 \%$ power when $10 \%$ of controls are exposed.

\section{RESULTS}

Study population

The GMC identified 63 cases. Two could not be traced in the relevant medical schools' archives, and two others were discarded because there was little or no information in their student records. The 59 remaining cases and 236 controls had completed their medical courses between 1958 and 1997, with most (205, 69\%) doing so between 1968 and 1987, 50 (17\%) between 1958 and 1967, and 40 (14\%) between 1988 and 1997.

The GMC matched cases and controls by the year of graduation. There were, however, variations in the years spent at medical school because of academic delay, intercalated degrees (optional one or two year courses taken within the medical course and leading to an additional non-medical degree), direct entry into the second year of a six year course, completion of a pre-medical school year, or transfers in from other universities. As a consequence, 90/236 control students $(38 \%)$ had a course entry year that was different to their relevant "case" student. This unavoidable difference was normally one year, although for 10 students it was two years.

\section{Descriptive analysis of the cohort}

Sociodemographic factors and "negative comments"-Most students were aged less than 21 at course entry and lived in the UK; there were few mature or overseas students (table 1). The cases were more likely to be men and from lower social class groups. There was little difference between the proportion of cases and controls with "relevant negative comments" in their academic references. Slightly more of the cases had missing or illegible data.

Performance on the medical course-Cases seemed more likely to have failed exams, repeated parts of the course, or had a lower overall level of performance than their peers, with a lower overall rating compared with their year matched controls (table 2). The records for the later, generally clinical, parts of the course tended to be more complete than records for the early parts. Once again the cases seemed to have performed less well. They were also more likely to have graduated late, usually because of the repetition of an early or preclinical year or the failure of final clinical examinations. We found no evidence of late graduation because of health or other personal reasons. There was a slightly higher incidence of "adverse remarks" in the cases, but no difference in the proportion gaining intercalated degrees.

Postgraduate progression-Data obtained from the GMC suggested that the cases were less likely to have achieved consultant status or to be on the general practice register. Overall, 189/236 (81\%) of the control group were either specialists or general practitioners compared with only 29/59 (49\%) of the cases (odds ratio for difference 4.16, 95\% confidence interval 2.8 to 7.6, $\mathrm{P}<0.001$, unmatched $\chi^{2}$ analysis). Unfortunately, these data are not fully robust because consultants who were in post before 1997 might not have applied to have their names added to the specialist register, and it is also possible that some general practitioners are not on the general practice register (personal communication from the GMC). We did not attempt to classify the doctors' specialties as they were diverse and numbers were too low to permit meaningful statistical analysis.

Alleged professional misconduct and subsequent sanctions -At the time of their GMC hearing, most cases (43/59, $73 \%$ ) had been qualified for 11-30 years, with three $(5 \%)$ for 10 years or less, and $13(22 \%)$ for 31-40 years. (The date of the actual misconduct was not supplied for all cases.) Table 3 summarises the type of alleged misconduct as classified by the GMC, together with an indication of the sanction imposed, as defined by them as the "case closure reason." "Other sanction" includes suspension, conditional registration, and case review. More details are provided in appendix 3 on bmj.com. These classifications were in

\section{Table 1|Sociodemographic characteristics and "negative comments" in references for students attending medical school who were later found guilty of serious professional misconduct (cases) or not (controls) after qualifying. Figures are numbers (percentages)}

\begin{tabular}{|c|c|c|c|}
\hline $\begin{array}{l}\text { Socioeconomic } \\
\text { characteristic }\end{array}$ & Control & Case & Overall \\
\hline \multicolumn{4}{|l|}{ Sex: } \\
\hline Male & $155(65.7)$ & $54(91.5)$ & $209(70.8)$ \\
\hline Female & $81(34.3)$ & $5(8.5)$ & $86(29.2)$ \\
\hline \multicolumn{4}{|l|}{ Domicile: } \\
\hline Home (UK) & $228(96.6)$ & $57(96.6)$ & $285(96.6)$ \\
\hline Overseas & $7(3.0)$ & $1(1.7)$ & $8(2.7)$ \\
\hline Not known & $1(0.4)$ & $1(1.7)$ & $2(0.7)$ \\
\hline \multicolumn{4}{|c|}{ Age group (years) at course entry*: } \\
\hline Younger («21) & $228(96.6)$ & $53(89.8)$ & $281(95.3)$ \\
\hline Older ( $\geq 21)$ & $8(3.4)$ & $6(10.2)$ & $14(4.7)$ \\
\hline \multicolumn{4}{|c|}{ Estimated social class (paternal occupation): } \\
\hline I & $44(18.6)$ & $7(11.9)$ & $51(17.3)$ \\
\hline II & $79(33.5)$ & $20(33.9)$ & $99(33.6)$ \\
\hline $\begin{array}{l}\text { III (manual or non- } \\
\text { manual) }\end{array}$ & $61(25.9)$ & $10(16.9)$ & $71(24.1)$ \\
\hline IV & $9(3.8)$ & $5(8.5)$ & $14(4.7)$ \\
\hline V & $5(2.1)$ & $6(10.2)$ & $11(3.7)$ \\
\hline Not known & $38(16.1)$ & $11(18.6)$ & $49(16.6)$ \\
\hline \multicolumn{4}{|c|}{ Negative comments present in student's reference: } \\
\hline None & $97(41.1)$ & $21(35.6)$ & $118(40.0)$ \\
\hline Minor & $58(24.6)$ & $14(23.7)$ & $72(24.4)$ \\
\hline Moderate & $29(12.3)$ & $7(11.9)$ & $36(12.2)$ \\
\hline Major & $7(3.0)$ & $2(3.4)$ & $9(3.1)$ \\
\hline Not known & $45(19.1)$ & $15(25.4)$ & $60(20.3)$ \\
\hline
\end{tabular}

*25 older files from one university had no data on age at admission. By examining date of final school qualification and date of course entrance, we deduced that 23 of these students were probably aged 17-18 and two were probably $\geq 21$. These were marked accordingly as $<21$ or $\geq 21$. 
Table 2 | Measures of performance during medical course for students attending medical school who were later found guilty of serious professional misconduct (cases) or not (controls) after qualifying. Figures are numbers (percentages)

\begin{tabular}{|c|c|c|c|}
\hline Performance measure & Control & Case & Overall \\
\hline \multicolumn{4}{|c|}{ Exams failed in early course: } \\
\hline No & $134(56.8)$ & $20(33.9)$ & $154(52.2)$ \\
\hline Yes & $70(29.7)$ & $32(54.2)$ & $102(34.6)$ \\
\hline Not known & $32(13.6)$ & 7 (11.9) & $39(13.2)$ \\
\hline \multicolumn{4}{|c|}{ Repeated parts of early course: } \\
\hline No & $192(81.4)$ & $40(67.8)$ & $232(78.6)$ \\
\hline Yes & $12(5.1)$ & $12(20.3)$ & $24(8.1)$ \\
\hline Not known & $32(13.6)$ & 7 (11.9) & $39(13.2)$ \\
\hline \multicolumn{4}{|c|}{ Relative performance on early course: } \\
\hline High & $22(9.3)$ & $2(13.4)$ & $24(8.1)$ \\
\hline Average & $143(60.6)$ & $27(45.8)$ & $170(57.6)$ \\
\hline Below average & $43(18.2)$ & $23(39.0)$ & $66(22.4)$ \\
\hline Not known* & 28 (11.9) & $7(11.8)$ & $35(11.8)$ \\
\hline \multicolumn{4}{|c|}{ Exams failed in later course: } \\
\hline No & $176(74.6)$ & $40(67.8)$ & $216(73.2)$ \\
\hline Yes & $55(23.3)$ & $19(32.2)$ & $74(25.1)$ \\
\hline Not known & $5(2.1)$ & $0(0)$ & $5(1.7)$ \\
\hline \multicolumn{4}{|c|}{ Repeated parts of later course: } \\
\hline No & $208(88.1)$ & $48(81.4)$ & $256(86.8)$ \\
\hline Yes & $21(8.9)$ & $11(18.6)$ & $32(10.8)$ \\
\hline Not known & $7(3.0)$ & $0(0)$ & $7(2.4)$ \\
\hline \multicolumn{4}{|c|}{ Relative performance on later course: } \\
\hline High & $24(10.2)$ & 7 (11.9) & $31(10.5)$ \\
\hline Average & $178(75.4)$ & $37(62.7)$ & $215(72.9)$ \\
\hline Below average & $32(13.6)$ & $15(25.4)$ & $47(15.9)$ \\
\hline Not known† & $2(0.9)$ & $0(0)$ & $2(0.7)$ \\
\hline \multicolumn{4}{|l|}{ Intercalated degree: } \\
\hline No & $211(89.4)$ & $52(88.1)$ & $263(89.2)$ \\
\hline Yes & $25(10.6)$ & $7(11.9)$ & $32(10.8)$ \\
\hline \multicolumn{4}{|c|}{ Slow progress (delayed graduation): } \\
\hline No & $214(90.7)$ & $43(72.9)$ & $257(87.1)$ \\
\hline Yes & $21(8.9)$ & $16(27.1)$ & $37(12.5)$ \\
\hline \multicolumn{4}{|l|}{ Adverse comments found: } \\
\hline No & $208(88.1)$ & $48(81.4)$ & $256(86.8)$ \\
\hline Yes & 28 (11.9) & $11(18.6)$ & $39(13.2)$ \\
\hline
\end{tabular}

*Three students with no detailed data on early performance had intercalated degrees so were classed as "high performers." One further student was noted in letter to have "average performance" even though no details were shown, so was classified as average.

tThree of five students with no information on clinical marks were noted from comments to have adequate performance. Two more with a single exam failure noted but no further details of marks were also said to have performed satisfactorily.

use between 1996 and 2006 and have since been updated, see www.gmc-uk.org). Only 23 cases (38\%) were clearly linked to clinical competence. The most common causes for complaint were other aspects of professional and personal behaviour, such as dishonesty and improper relationships.

\section{Conditional regression analyses}

Univariate analysis - Table 4 shows that male sex, lower estimated social class, difficulties in early/preclinical course, and delayed graduation were associated with case status. There was a less significant association with poorer progress in the clinical course.

Multivariable analysis - Table 5 shows the first multivariable model, with all explanatory variables included, and the final model. Male sex, low social class, and failure of preclinical examinations were all independently associated with subsequent professional misconduct

Imputation of missing data-Repetition of the regression analysis after imputation of missing data confirmed our findings, though with lower values for odds ratios but narrower confidence intervals. The final multivariate model identified male sex (odds ratio 5.57, 95\% confidence interval 2.03 to $15.25, \mathrm{P}=0.001)$, lower social class $(3.19,1.29$ to $7.87, \mathrm{P}=0.012)$, and early/preclinical examination failures $(3.21,1.43$ to $7.23, \mathrm{P}=0.005)$ as independent risk factors.

\section{DISCUSSION}

This small preliminary study provides the first evidence in the UK that male students and those who perform poorly in the early years of the course, for whatever reason, might be at a slightly increased risk of subsequent professional misconduct. Lower social class (as estimated from father's occupation at course entry) was also an independent risk factor in this retrospective study. This finding, however, could reflect social influences operating up to 40 years ago. Furthermore, as with all such studies examining risk factors for an adverse outcome, most individuals "at risk" will not have that outcome.

Our data also indicate that the "case" doctors might have a less successful career, in terms of gaining consultant status or being on the general practice register, although this conclusion is less robust and merits further study.

\section{Strengths and limitations}

We avoided recall bias by using data recorded in the medical school records before the individual qualified as a doctor and therefore before any professional misconduct. We extracted data from the records without knowing the individual's status as case or control. All eligible cases and controls were included, which reduced selection bias. Though we therefore believe that our conclusions are robust, they must be interpreted with caution because of the unavoidable limitations inherent in the study.

We studied doctors from only eight UK medical schools. We were constrained by institutional policies on data retention and expressions of interest. The small sample size is reflected in wide confidence intervals. In addition, the study focused on the individual. We could not study the effects of individual medica schools as these were used in the matching procedure for cases and controls and the subsequent analysis. The character and ethos of each might have changed over such long periods and could have influenced the results.

Controls were matched by qualification year, although $38 \%$ of the controls did not have the same year of entry to medical school as their corresponding 
Table 3 | Summary of alleged professional misconduct and sanctions

\begin{tabular}{lcccc} 
& No of doctors & \multicolumn{3}{c}{ Sanctions applied } \\
\cline { 2 - 5 } Type of misconduct* & $\begin{array}{c}\text { Erasure or erasure with } \\
\text { immediate suspension }\end{array}$ & $\begin{array}{c}\text { Admonished or } \\
\text { reprimanded }\end{array}$ & $\begin{array}{c}\text { Other } \\
\text { sanction }\end{array}$ \\
\hline Dishonesty & $7(12)$ & 1 & 2 & 4 \\
\hline Dishonesty/criminality & $14(24)$ & 10 & 0 & 4 \\
\hline Dysfunctional conduct & $6(10)$ & 2 & 1 & 3 \\
\hline Sexual assault or indecency & $3(5)$ & 2 & 6 & 6 \\
\hline Substandard clinical practice and care & $16(27)$ & 4 & 3 & 3 \\
\hline Treatment & $7(12)$ & 1 & 4 & 2 \\
\hline Other & $6(10)$ & 0 & & - \\
\hline
\end{tabular}

*As classified by GMC between December 1996 and April 2006.

case. The match was generally correct within one year of entry, and we cannot think of any a priori reason why the discrepancies should have affected the final analysis.

We studied doctors with a GMC hearing within a relatively short time span, 1999-2004. "Cases" will have been seen from all the participating medical

Table $4 \mid$ Univariate analyses (conditional logistic regression) of selected explanatory variables against outcome of being "case"

\begin{tabular}{|c|c|c|c|c|}
\hline Factor & Controls & Cases & Odds ratio $(95 \% \mathrm{Cl})$ & Pvalue* \\
\hline \multicolumn{5}{|l|}{ Sex: } \\
\hline Male & 155 & 54 & $5.69(2.18$ to 14.80$)$ & $<0.001$ \\
\hline Female & 81 & 5 & - & \\
\hline \multicolumn{5}{|l|}{ Age at course entry: } \\
\hline Older ( $\geq 21)$ & 8 & 6 & $3.00(1.04$ to 8.65$)$ & 0.04 \\
\hline Younger («21) & 228 & 53 & - & \\
\hline \multicolumn{5}{|l|}{ Estimated social class: } \\
\hline Lower (IV-V) & 14 & 11 & 3.77 (1.54 to 9.25$)$ & 0.004 \\
\hline Higher (I-III) & 184 & 38 & - & \\
\hline \multicolumn{5}{|l|}{ Failed exams in early/preclinical course: } \\
\hline Yes & 70 & 32 & $3.35(1.70$ to 6.60$)$ & $<0.001$ \\
\hline No & 134 & 20 & - & \\
\hline \multicolumn{5}{|c|}{ Repeated parts of early/preclinical course: } \\
\hline Yes & 12 & 12 & $5.30(2.04$ to 13.74$)$ & 0.001 \\
\hline No & 192 & 40 & - & \\
\hline \multicolumn{5}{|c|}{ Poor performance in early/preclinical course, relative to peers: } \\
\hline Yes (poor performance) & 43 & 23 & $2.92(1.51$ to 5.64$)$ & 0.001 \\
\hline No (average or high performance) & 165 & 30 & - & \\
\hline \multicolumn{5}{|l|}{ Failed exams in later/clinical course: } \\
\hline Yes & 55 & 19 & 1.56 (0.82 to 2.96$)$ & 0.17 \\
\hline No & 176 & 40 & - & \\
\hline \multicolumn{5}{|l|}{ Repeated parts of later/clinical course: } \\
\hline Yes & 21 & 11 & 2.37 (1.03 to 5.43$)$ & 0.04 \\
\hline No & 208 & 48 & - & \\
\hline \multicolumn{5}{|c|}{ Poor performance in later/clinical course, relative to peers: } \\
\hline Yes (poor performance) & 32 & 15 & 2.09 (1.06 to 4.13) & 0.03 \\
\hline No (average or high performance) & 202 & 44 & - & \\
\hline \multicolumn{5}{|l|}{ Normal progress through course: } \\
\hline No & 21 & 16 & $4.06(1.84$ to 8.96$)$ & 0.001 \\
\hline Yes & 214 & 43 & - & \\
\hline \multicolumn{5}{|l|}{ Adverse comments found: } \\
\hline Yes & 28 & 11 & $1.97(0.82$ to 4.75$)$ & 0.13 \\
\hline No & 208 & 48 & - & \\
\hline
\end{tabular}

schools before and after these dates. Even within this period, a few doctors might have requested, and been granted, voluntary erasure from the medical register and therefore not have been included in our database (although it should be noted that the decision to grant voluntary erasure is made after consideration of whether there is a public interest in the exposure of serious allegations, with a realistic prospect of establishing impaired fitness to practise).

In addition, the GMC excluded from our series any doctors whose health was a contributory cause of misconduct. The potential effect of these missing cases on our analysis is unknown and could have had an influence on the results. Certainly we know that health is a factor affecting progress in medical students. ${ }^{11}$

The quality and completeness of the data was variable. The analysis after imputation, however, suggests that our results are valid and not overly affected by the missing data. In addition, a recent review of the use of imputation suggests that the type of missing data in our dataset (that the reasons are unrelated to the outcome variable) should not bias the non-imputed results. ${ }^{13}$

Our sample size was too small for consideration of different categories of misconduct or the potential effects of different specialties. This reduces the generalisability of the study.

\section{Interpretation of the study}

Despite the absence of comparable studies in the UK, our findings can be viewed in the context of other evidence. An earlier study noted a preponderance of men in internal disciplinary hearings in one health region, ${ }^{14}$ and recent statistics from the National Clinical Assessment Authority show higher referral rates for male doctors, after allowance for workforce proportions, age, and specialty. ${ }^{15}$ Several studies of American physicians disciplined by state medical boards also show an association with male sex, ${ }^{16-19}$ although some do not. ${ }^{910}$ Differences in personality and consulting style have been suggested as contributory reasons for an increase in complaints. ${ }^{2021}$ Medical specialty might be a relevant confounder, but we were unable to investigate this. Even within a single specialty there might be differences by sub-specialty. ${ }^{18}$

We were unable to investigate the possible effects of ethnicity as these data were not available. Ethnic 
Table 5| Multivariable conditional logistic regression of explanatory variables against outcome of being "case"

\begin{tabular}{|c|c|c|}
\hline Factor & Adjusted odds ratio* $(95 \% \mathrm{Cl})$ & $P$ value* \\
\hline \multicolumn{3}{|l|}{ First model, all variables } \\
\hline Male sex & 8.95 (1.99 to 40.32$)$ & 0.004 \\
\hline Lower estimated social class (IV or V) & 4.63 (1.49 to 14.38$)$ & 0.008 \\
\hline Age at course entry $(\geq 21)$ & $2.14(0.22$ to 20.81$)$ & 0.51 \\
\hline Failed exams in early/preclinical course & 3.94 (1.01 to 15.29$)$ & 0.047 \\
\hline Repeated parts of early course & 2.08 (0.19 to 23.37$)$ & 0.55 \\
\hline Poor performance in early course, relative to peers & $1.04(0.23$ to 4.81$)$ & 0.96 \\
\hline Failed exams in later/clinical course & $1.05(0.26$ to 4.14$)$ & 0.95 \\
\hline Repeated parts of later/clinical course & $2.48(0.41$ to 14.96$)$ & 0.32 \\
\hline $\begin{array}{l}\text { Poor performance in later/clinical course, relative to } \\
\text { peers }\end{array}$ & 0.55 (0.11 to 2.67$)$ & 0.46 \\
\hline Slow progress through course & $1.23(0.12$ to 12.49$)$ & 0.86 \\
\hline Adverse comments found & $1.30(0.28$ to 6.03$)$ & 0.74 \\
\hline \multicolumn{3}{|l|}{ Final model } \\
\hline Male sex & 9.80 (2.43 to 39.44$)$ & 0.001 \\
\hline Lower estimated social class & 4.28 (1.52 to 12.09$)$ & 0.006 \\
\hline Failed exams in early/preclinical course & 5.47 (2.17 to 13.79$)$ & $<0.001$ \\
\hline
\end{tabular}

minority status is known to influence performance at medical school ${ }^{112223}$ and future attainment ${ }^{24}$ and merits further study.

Complaints of professional misconduct might be affected by social biases-for example, an assumption that men were more likely than women to exhibit aggressive behaviour or to commit sexual misconduct, therefore a higher proportion of men might be referred. In our study, however, we focused only on those with proved misconduct, and it has to be assumed that the GMC's rigorous examination of evidence would rule out spurious or discriminatory claims.

The effect found for a lower social class background is a sensitive finding and one that is not mentioned elsewhere in the literature with respect to the professional performance of doctors. We have no explanation for our findings, which could be potentially relevant to current initiatives to "widen access" to medicine within communities that traditionally have not been represented in the medical profession. ${ }^{2526} \mathrm{We}$ do not want to suggest that such students should be viewed differently from any others because we have shown only a relative risk, and the absolute risk for an individual from any background is small. Social class is also the least statistically significant of the three risk factors identified. Our data must be viewed in context; $86 \%$ of the doctors in our study graduated at least 20 years ago, when life at medical school and in the profession might have been different. Also, social class is both notoriously difficult to define and subject to frequent re-evaluation. ${ }^{127}$ It is even possible that we were actually measuring some other influence for which estimated social class was only a proxy. Nevertheless, we speculate that students who were socially "different" from their peers might have suffered some discrimination in the past. The "hidden curriculum" in medical education-including negative role modelling and stereotypical behaviour-is known to have adverse effects on students' ability to learn ${ }^{28}$ and to develop into competent professionals. ${ }^{29-31}$ Within the NHS, workplace bullying and harassment might still happen, ${ }^{32}$ particularly to doctors from ethnic minorities ${ }^{33}$ and potentially to those from other minority backgrounds. A recent qualitative study of students from lower socioeconomic groups found a stereotypical view of the medical profession as "posh" and unattainable. ${ }^{34}$ This could perhaps result in apprehension and a lack of self confidence at medical school, leading to a lowered ability to integrate and adopt professional behaviours.

We were not surprised by the increased risk suggested by poor examination results in the early medical course and the possible association of a less successful career with professional misconduct. Other evidence supports an association between early academic achievement and overall success at medical school ${ }^{1122}$ and beyond ${ }^{35}$ in the UK; studies of board certification rates in the US provide similar conclusions. ${ }^{103637}$ Slow overall progress on the course was not significant overall, but the practice of individual universities in requiring repetition of parts of the course varied, both between institutions and over time, so this might be an imprecise variable.

In our pilot study in Nottingham we found an association between "negative comments" and caseness (unpublished observations). This finding was not confirmed in this multicentre study. The analysis was weakened by the variability of the unstructured academic references and by missing data in older or less legible files. The academic reference is no longer confidential, in that it is shared with the student, so we think it will be unlikely to contain pertinent critical comments in future. We did not find any statistical association between documented unprofessional behaviour on the course and subsequent misconduct, as has been reported elsewhere. ${ }^{910}$ Many of the older files, however, had no free text data at all, and medical schools have historically had no requirement to document misconduct in a uniform way. Current guidance from the GMC now encourages the detection and reporting of poor behaviour. ${ }^{38}$

\section{Issues for consideration}

Poorly performing students who are identified early in the course should receive additional support and mentoring by experienced and skilled tutors. This could include counselling and exploration of sensitive issues, perhaps by non-medical school staff to enhance the students' willingness to seek and receive confidential help. ${ }^{39}$ Our data suggest that there might be longer term benefits from this input. Recent research has shown that students from non-traditional backgrounds are helped by additional personalised support. ${ }^{40}$

Medical schools are already required by the GMC to have clear guidelines for decisions regarding fitness to practise.$^{38}$ If our findings were to be replicated by larger studies, this would add weight to the robust defence 


\section{WHAT IS ALREADY KNOWN ON THIS TOPIC}

Complaints about professional misconduct by doctors in the UK might require them to appear before the General Medical Council fitness to practise panels

Male doctors are more likely to have complaints made against them

Studies in America suggest that professional misconduct could be linked to poor performance or unprofessional behaviour at medical school, but there is no comparable evidence from the UK

\section{WHAT THIS STUDY ADDS}

This preliminary case-control study found that male sex, lower estimated social class, and poor early performance at medical school were independent risk factors for subsequent professional misconduct of decisions based on such GMC derived guidelines in cases where students exhibit recurrent serious failings.

Longitudinal tracking of doctors' careers, impossible at present, would aid research and might ultimately improve care of patients by improving support to young doctors who were identified as being less successful or having attitudinal problems. One way to begin this process might be to develop a standardised confidential system of communication from medical schools through deaneries to employing trusts.

\section{Further research}

Further studies, with larger cohorts and a longer time span for the identification of cases, are required to confirm or refute these findings. The associations between sociodemographic factors and misconduct, especially the sensitive issues of social background and possible harassment or bullying, need to be investigated. The possible influences of ethnicity and of specific medical schools need to be studied. It would also be important to explore the predictors of different types of misconduct and the associations, if any, between misconduct and career specialties.

We are indebted to Carol Coupland, associate professor in medical statistics, Community Health Sciences, who carried out the conditional regression and data imputation, and interpreted the resulting data. We thank staff at the General Medical Council: Peter Rubin, Chris Gulik, and Nicola Costin for securing funding from the GMC's research and development advisory board, and for coordinating support; and Adrian McAndrew and Kate Walmsley for identifying cases and controls, liaising with our partner medical schools, and extracting data from the GMC databases. We thank staff at our partner medical schools: Allan Cumming Ruth Stewart (Edinburgh); Jill Morrison, Caroline Mallon (Glasgow); Trudie Roberts, Deborah Murdoch-Eaton (Leeds); Stewart Petersen (Leicester) Elizabeth Sheader, Tim Dornan (Manchester); Suzanne Cholerton, Dianorah Smith (Newcastle); and Nigel Bax, Denise Bee (Sheffield); and the administrative staff of all institutions. Finally, we thank our colleagues from Nottingham: Robert Wilcox, Charles Marsden, and David James for reviewing the academic statements; Eamonn Ferguson for discussions about the analysis and implications of the results; and David Yates for helping to classify parental occupations.

Contributors: Both authors developed the idea for the study, negotiated with the GMC contributed to the paper and approved the final draft. IY prepared the database, conducted the initial analysis, wrote the first draft of the paper, and is guarantor. Senior staff at our partner universities were invited to comment on a late draft of the paper.

Funding: The external costs of the study (photocopying and anonymising student files and transporting them to Nottingham) were funded by the GMC. JY was funded by the Service Increment for Teaching (SIFT). Role of the study sponsors: The GMC agreed to the design of the study and provided the names of cases and controls to participant medical schools in confidence. It had no role in the collection and analysis of data, nor the interpretation of the results. The GMC accepted a full report of the study in July 2009 and agreed to the submission this paper. Competing interests: All authors have completed the Unified Competing Interest form at www.icmje.org/coi_disclosure.pdf (available on request from the corresponding author) and declare that: (1) JY and DJ have support from the General Medical Council for the submitted work; (2) JY and DJ have had no relationships in the previous 3 years with any other Companies that might have an interest in the submitted work; (3) their spouses, partners, or children have no financial relationships that may be relevant to the submitted work; and (4) JY and DJ have no non-financial interests that may be relevant to the submitted work.

Ethical approval: This study was approved by the University of Nottingham research ethics committee (ref A/12/2007) and the research ethics committees of all participating universities

Data sharing: Additional data (manipulation of social class and examination data, description of GMC case categories, and anonymised list of actual cases) are available in supplemental files from the authors ( janet.yates@nottingham.ac.uk). Raw data are not available.

1 The Shipman Inquiry. Safeguarding patients: lessons from the past, proposals for the future. Stationery Office, 2004.

2 Bristol Royal Infirmary Inquiry. Learning from Bristol: the report of the public inquiry into children's heart surgery at the Bristol Royal Infirmary, 1984-85. Stationery Office, 2001.

3 General Medical Council. Referring a doctor to the GMC: a guide for individual doctors, medical directors and clinical governance managers. GMC, 2004.

4 General Medical Council. Tomorrow's doctors. GMC, 2003.

5 Medical Schools Council. Guiding principles for the admission of medical students-revised. 2006. www.medschools.ac.uk/ Publications/Pages/Guiding-Principles-Medical-Students.aspx.

6 Ben-David M, Snadden D, Hesketh A. Linking appraisal of PRHO professional competence of junior doctors to their education. Med Teach 2004;26:63-70.

7 Wilkinson J, Crossley J, Wragg A, Mills P, Cowan G, Wade W. Implementing workplace-based assessment across the medical specialties in the United Kingdom. Med Educ 2008;42:364-73.

8 Davies H, Archer J, Southgate L, Norcini J. Initial evaluation of the first year of the foundation assessment programme. Med Educ 2009;43:74-81.

9 Papadakis M, Hodgson C, Teherani A, Kohatsu N. Unprofessional behavior in medical school is associated with subsequent disciplinary action by a state medical board. Acad Med 2004;79:244-9.

10 Papadakis M, Teherani A, Banach M, Knettler T, Rattner S, Stern D, et al. Disciplinary action by medical boards and prior behaviour in medical school. N Engl J Med 2005;353:2673-82.

11 Yates J, James D. Predicting the "strugglers": a case-control study of students at Nottingham University Medical School. BMJ 2006;332:1009-13.

12 Rose D. Official social classifications in the UK. University of Surrey 1995.

13 Sterne J, White I, Carlin J, Spratt M, Royston P, Kenward M, et al. Multiple imputation for missing data in epidemiological and clinical research: potential and pitfalls. BMJ 2009;338:b2393.

14 Donaldson L. Doctors with problems in an NHS workforce. BM 1994;308:1277-82.

15 National Clinical Assessment Service. Analysis of the first four years referral data. NHS National Patient Safety Agency, 2006.

16 Taragin M, Wilczek A, Karns M, Trout R, Carson J. Physician demographics and the risk of medical malpractice. Am J Med 1992;93:537-42.

17 Morrison J, Wickersham P. Physicians disciplined by a state medical board. JAMA 1998;279:1889-93.

18 Morrison J, Morrison T. Psychiatrists disciplined by a state medical board. Am J Psychol 2001:158:474-8.

19 Kohatsu N, Gould D, Ross L, Fox P. Characteristics associated with physician discipline. Arch Intern Med 2004;164:653-8.

20 Firth-Cozens I. Effects of gender on performance in medicine. $B M$ 2008;336:731-2.

21 Kinnersley P, Edwards A. Complaints against doctors. BMJ 2008;336:841-2.

22 Yates J, James D. Risk factors for poor performance on the undergraduate medical course: cohort study at Nottingham University. Med Educ 2007; 41:65-73.

23 Liddell M, Koritsas S. Effect of medical students' ethnicity on their attitudes towards consultation skills and final year examination performance. Med Educ 2004;38:187-98.

24 Silber C, Veloski J. Board certification in obstetrics and gynecology: associations with physicians' demographics and performances during medical school. Am J Obstet Gynecol 2005;192:318-22. 
25 Department for Education and Skills. The future of higher education. DfES, 2003.

26 Angel C, Johnson A. Broadening access to undergraduate medical education. BMJ 2000;321:1136-8.

27 Office for National Statistics. Self-coded version of the NS-SEC. 2008 www.ons.gov.uk/about-statistics/classifications/current/ns-sec/ self-coded/index.html.

28 Woolf K, Cave J, Greenhalgh T, Dacre J. Ethnic stereotypes and the underachievement of UK medical students from ethnic minorities: qualitative study. BMJ 2008;337:a1220.

29 Lempp H, Seale C. The hidden curriculum in undergraduate medical education: qualitative study of medical students' perceptions of teaching. BMJ 2004;329:770-3.

30 Stephenson A, Adshead L, Higgs R. The teaching of professional attitudes within UK medical schools: reported difficulties and good practice. Med Educ 2006;40:1072-80.

31 D'Eon M, Lear N, Turner M, Jones C. Perils of the hidden curriculum revisited. Med Teach 2007;29:295-6.

32 Paice E, Aitken M, Houghton A, Firth-Cozens J. Bullying among doctors in training: cross sectional questionnaire survey. $B M J$ 2004;329:658-9.

33 Paice E, Smith D. Bullying of trainee doctors is a patient safety issue. Clin Teach 2009;6:13-7.
34 Greenhalgh T, Seyan K, Boynton P. "Not a university type": focus group study of social class, ethnic, and sex differences in school pupils' perceptions about medical school. BMJ 2004;328:1541-7.

35 McManus I, Smithers E, Partridge P, Keeling A, Fleming P. A levels and intelligence as predictors of medical careers in UK doctors: 20 year prospective study. BMJ 2003;327:139-42.

36 Xu G, Veloski J, Hojat M. Board certification: association with physicians' demographics and performances during medical schoo and residency. Acad Med 1998;73:1283-9.

37 Papadakis M, Arnold G, Blank L, Holmboe E, Lipner R. Performance during internal residency training and subsequent disciplinary action by state licensing boards. Ann Intern Med 2008;148:869-76.

38 General Medical Council and Medical Schools Council. Medical students: professional values and fitness to practise. GMC, 2009.

39 Cleland J, Arnold R, Chesser A. Failing finals is often a surprise for the student but not the teacher: identifying difficulties and supporting students with academic difficulties. Med Teach 2005;27:504-8.

40 Garlick P, Brown G. Widening participation in medicine. BMJ 2008;336:1111-3.

Accepted: 9 March 2010 